\title{
Photoluminescence and Structural Properties of ZnO Nanorods Growth by Assisted-Hydrothermal Method
}

\author{
S. López-Romero*, M. García-H \\ Instituto de Investigaciones en Materiales, Universidad Nacional Autónoma de México, Circuito Interior S/N Ciudad Universitaria, \\ México DF, México. \\ Email: ${ }^{*}$ sebas@servidor.unam,mx
}

Received March $6^{\text {th }}, 2013$; revised May $26^{\text {th }}, 2013$; accepted June $7^{\text {th }}, 2013$

Copyright (C) 2013 S. López-Romero, M. García-H. This is an open access article distributed under the Creative Commons Attribution License, which permits unrestricted use, distribution, and reproduction in any medium, provided the original work is properly cited.

\begin{abstract}
Semiconducting zinc oxide ( $\mathrm{ZnO})$ nanorods were obtained in bulk quantity by an hexamethylenetetramine (HMTA)assisted hydrothermal method at low temperature $\left(90^{\circ} \mathrm{C}\right)$ with methenamine $\left(\left(\mathrm{CH}_{3}\right)_{6} \mathrm{~N}_{4}\right.$ as surfactant and catalyst and zinc nitrate $\mathrm{Zn}\left(\mathrm{NO}_{3}\right)_{2} \cdot 6 \mathrm{H}_{2} \mathrm{O}$ as $\mathrm{Zn}$ source. The structure and phase of $\mathrm{ZnO}$ nanorods were studied using X-ray diffraction (XRD) and high resolution transmission electron microscopy techniques (HRTEM). The morphology of the nanostructures was studied by scanning electron microscope (SEM) method. The photoluminescence (PL) properties were investigated founding two emission bands under UV excitation.
\end{abstract}

Keywords: ZnO; Nanorods; Assisted-Hydrothermal Method; Photoluminescence

\section{Introduction}

Zinc oxide is one of the oldest metallic oxides semiconductors studied because its important optical and electronics properties such as: a wide band gap $(3.37 \mathrm{eV})$ and high exciton binding energy $(60 \mathrm{meV})$, moreover, these properties can be utilized in several $\mathrm{ZnO}$ complex nanostructures to the fabrication of blue emitting lasers [1], transparent semiconductors [2,3], piezoelectric devices [4], short-wavelength light emitting devices [5], blue emitting LEDs [6], chemical sensors [7], solar cells [8], magnetic structures [9], etc. $\mathrm{ZnO}$ in varied complex forms has been synthesized by several methods such as chemical vapor deposition on pure $\mathrm{Si}$ substrate [10], low-temperature wet-chemical methods [11], thermal evaporation [12], hydrothermal synthesis [13,14], rf magnetron sputtering [15,16], molecular bean epitaxy [17,18], pulsed-laser deposition $[19,20]$. Actually, many complex nanostructures of the Zinc oxide semiconductor $(\mathrm{ZnO})$ has been synthesized by different methods such has nanocombs [21,22], nanorings [23], nanohelixes/nanosprings [24,25], nanobelts [26], nanocages [27], flower-like [28], and nanorod-like systems [29-32], this last class of nanostructures are the best system for understand the transport mechanism in one-dimensional (1D) materials,

"Corresponding author. so as for developing news nanodevices wit best properties and performance. There exist various methods to obtain nanorods such as: vapour-liquid-solid (VLS) process [29,33,34], anodic alumina template [35], metalorganic vapor-phase epitaxial growth (MOVPE) [36,37], thermal evaporation method [31,38-41], spray pyrolysis technique [42], thermal decomposition reaction in solvent [43], micro-emulsion growth [44], and soft chemical method $[45,46]$, this last method with low-cost, let a effective control of the variables that announce in the $1 \mathrm{D} \mathrm{ZnO}$ nanoscale materials synthesis, it is necessary to the preparation of small diameter nanorods (diameter < $100 \mathrm{~nm}$ ) used in the obtaining of nanodevices with goods properties opto-electronics. In this work, by means of an soft chemical assisted-hydrothermal method, $\mathrm{ZnO}$ nanorods were synthesized at low temperature $\left(90^{\circ} \mathrm{C}\right)$ using as source materials Zinc Nitrate $\mathrm{Zn}\left(\mathrm{NO}_{3}\right)_{2} \cdot 6 \mathrm{H}_{2} \mathrm{O}$ as $\mathrm{Zn}$ source and methenamine $\left(\left(\mathrm{C}_{6} \mathrm{H}_{12}\right) \mathrm{N}_{4}\right)$ as surfactant and catalyst.

\section{Experimental Details}

\subsection{Materials}

The chemical reagents used in this research were analytic reagent grade (Sigma-Aldrich) and used as received without further purification. 


\subsection{Preparation of Nanorods Nanostructures}

\section{Reaction Mechanism}

The solution precursor was prepared using zinc nitrate $\left(\mathrm{Zn}\left(\mathrm{NO}_{3}\right)_{2} \cdot 6 \mathrm{H}_{2} \mathrm{O}\right)$ as $\mathrm{Zn}$ and $\mathrm{O}$ sources and hexamethylenetetramine $\left[\left(\mathrm{CH}_{3}\right)_{6} \mathrm{~N}_{4}\right]$ as surfactant and catalyst under the hydrothermal reaction mechanism proposed by Zhung and coworkers [47], which found that the $\left[\mathrm{Zn}(\mathrm{OH})_{4}\right]^{2-}$ radical play a important role in the $\mathrm{ZnO}$ nanorods assistedhydrothermal synthesis, merely, the $\left[\mathrm{Zn}(\mathrm{OH})_{4}\right]^{2-}$ radical produce $\mathrm{ZnO}$ nanorods under the chemical reactions follow:

$$
\mathrm{Zn}\left(\mathrm{NO}_{3}\right)_{2}+2 \mathrm{H}_{2} \mathrm{O} \stackrel{\left(\mathrm{CH}_{3}\right)_{6} \mathrm{~N}_{4}, 90{ }^{\circ} \mathrm{C}}{\longrightarrow} \mathrm{Zn}(\mathrm{OH})_{2}+2 \mathrm{HNO}_{3}
$$

$$
\begin{gathered}
\mathrm{Zn}(\mathrm{OH})_{2} \leftrightarrow \mathrm{Zn}^{2+}+2 \mathrm{OH}^{-} \\
\mathrm{Zn}^{2+}+2 \mathrm{OH}^{-} \leftrightarrow \mathrm{ZnO}+\mathrm{H}_{2} \mathrm{O} \\
\mathrm{Zn}(\mathrm{OH})_{2}+2 \mathrm{OH}^{-} \leftrightarrow\left[\mathrm{Zn}(\mathrm{OH})_{4}\right]^{2-}
\end{gathered}
$$

Finally, the growth unites of $\left[\mathrm{Zn}(\mathrm{OH})_{4}\right]^{2-}$ radicals produced in reaction (4) under the dissolution-nucleation cycle produce $\mathrm{ZnO}$ nanorods by means of Equations (5) an (6) follow:

$$
\begin{array}{r}
{\left[\mathrm{Zn}(\mathrm{OH})_{4}\right]^{2-} \leftrightarrow \mathrm{Zn}^{2-}+4 \mathrm{OH}^{-}} \\
\mathrm{Zn}^{2+}+2 \mathrm{OH} \leftrightarrow \mathrm{ZnO}+\mathrm{H}_{2} \mathrm{O}
\end{array}
$$

A resumed equation can be obtained to effect of stoichiometric calculus as follow:

$$
\mathrm{Zn}\left(\mathrm{NO}_{3}\right)_{2}+2 \mathrm{H}_{2} \mathrm{O} \stackrel{\left(\mathrm{CH}_{3}\right)_{6} \mathrm{~N}_{4}, 90^{\circ} \mathrm{C}}{\longrightarrow} \mathrm{ZnO}+2 \mathrm{HNO}_{3}+\mathrm{H}_{2} \mathrm{O}
$$

The chemical Equation (7) was used to obtain $1 \mathrm{~g}$ of $\mathrm{ZnO}$ powder, merely, the solution reaction was prepared by dissolving $2 \mathrm{~g}$ of Zinc nitrate and $1.5 \mathrm{~g}$ of methenamine in deionized water under vigorous stirring at $50^{\circ} \mathrm{C}$ for $1 \mathrm{~h}$ to form a $0.01 \mathrm{M}$ equimolar solution, then the reaction solution was heated at $90^{\circ} \mathrm{C}$ for 2 hours. After $20 \mathrm{~min}$ it was observed a white $\mathrm{ZnO}$ powder precipitated on the flask bottom. Finally, the $\mathrm{ZnO}$ white powder were thoroughly washed with deionized water and allowed to dry in air at room temperature.

\section{Characterization}

The $\mathrm{ZnO}$ nanorods thus obtained were further characterized structurally by X-ray diffraction (XRD) technique using a SIEMENS D 5000 diffractometer using the $\mathrm{CuK} \alpha(1.5406 \AA)$ radiation, with a scanning speed of $1^{\circ}$ per min at $35 \mathrm{KV}$ and $30 \mathrm{~mA}$. The single-crystal structure of the $\mathrm{ZnO}$ nanorods was observed using a JEOL FAG 2010 Fast TEM electron microscopy with a $2.1 \AA$ resolution (point to Point), the morphology was studied using a JEM5600-LV scanning electron microscopy (SEM), the room temperature photoluminescence (PL) spectra were performed using a $\mathrm{He}: \mathrm{Cd}$ laser with a wavelength of $328 \mathrm{~nm}$.

\section{Results and Discussion}

Figure 1 shows the XRD pattern of the $\mathrm{ZnO}$ nanorods prepared by the HMTA assisted hydrothermal method, the diffraction pattern correspond to the $\mathrm{ZnO}$ with wurtzite structure (hexagonal phase space group $\mathrm{P}_{3 \mathrm{mc}}$ ). All of the diffraction peaks of the samples were indexed to the hexagonal phase of $\mathrm{ZnO}$ having lattice parameters a $=$

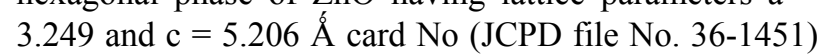
in good agreement with the data from the Join Committee of Powder Diffraction Standards (JPDS). No other diffraction peaks from $\mathrm{Zn}(\mathrm{NO})_{2} \cdot 6 \mathrm{H}_{2} \mathrm{O}$ and $\mathrm{Zn}(\mathrm{OH})_{2}$ or other impurities have been found in the samples.

Figure 2 shows the morphology of the $\mathrm{ZnO}$ nanorods obtained by means of scanning electron micrographs SEM, Figures 2(a) and (b) are a top view of the $\mathrm{ZnO}$ nanorods, which show that the product is formed by crystals with rod-like a uniform diameter of about 400

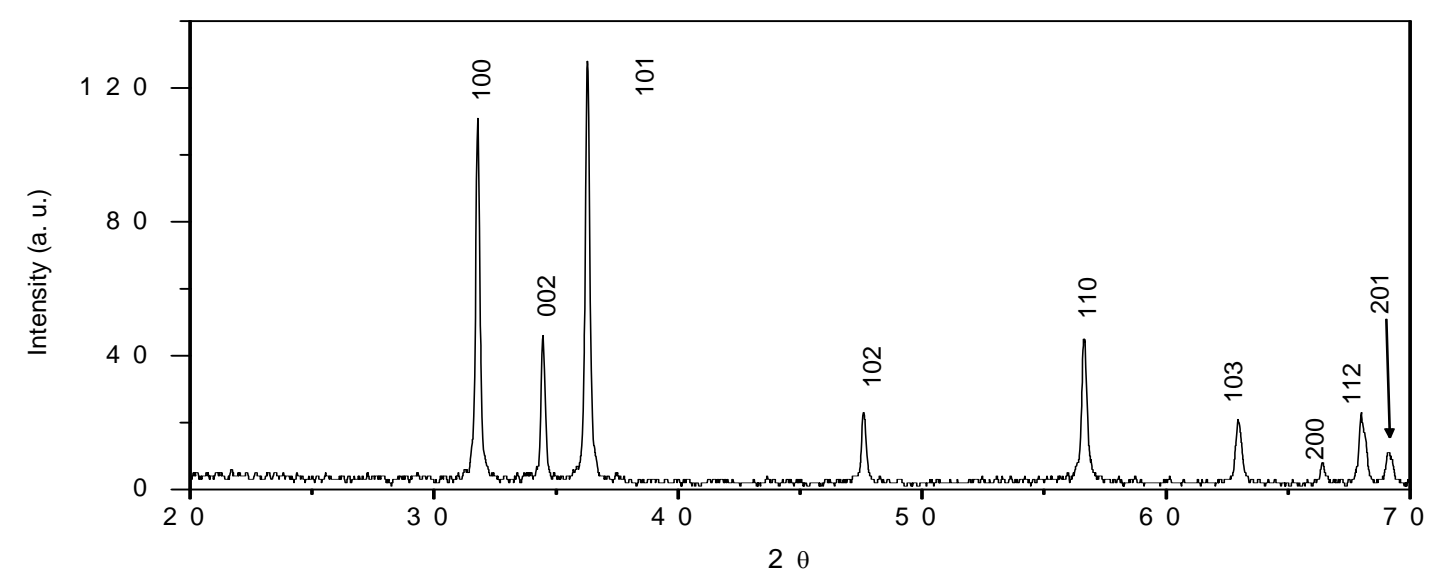

Figure 1. Diffraction pattern of the nanorods $\mathrm{ZnO}$ nanostructures. 


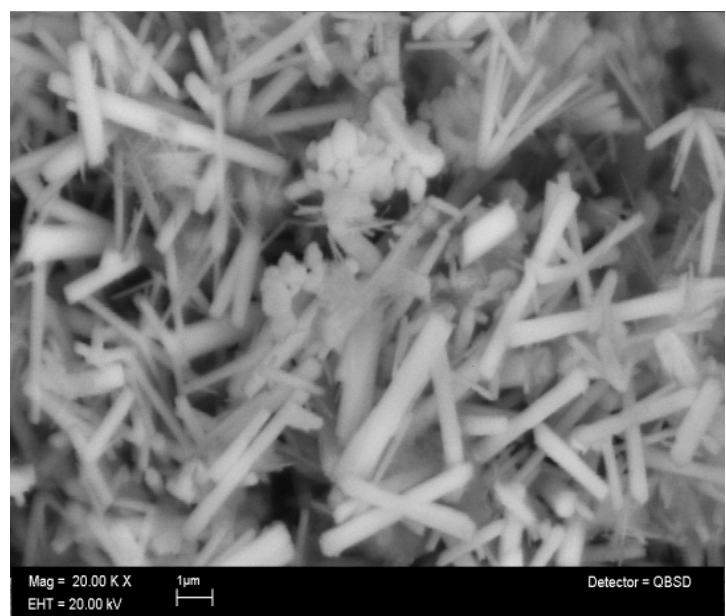

(a)

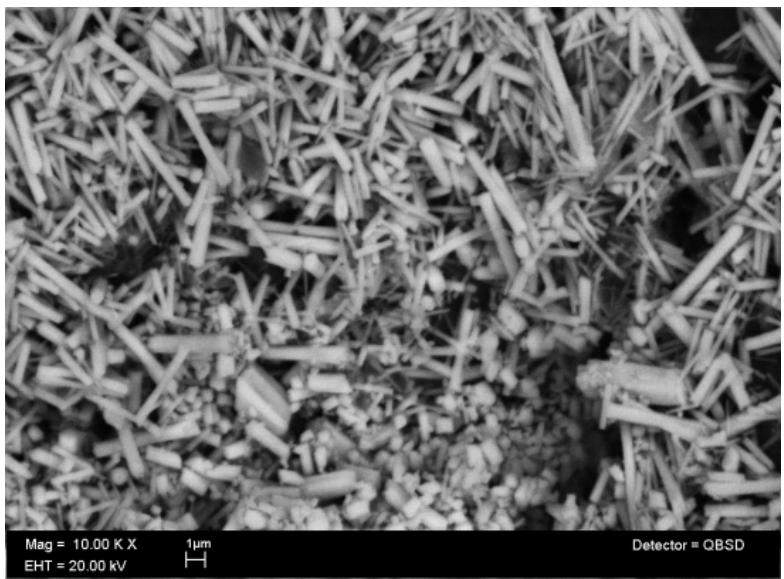

(c)

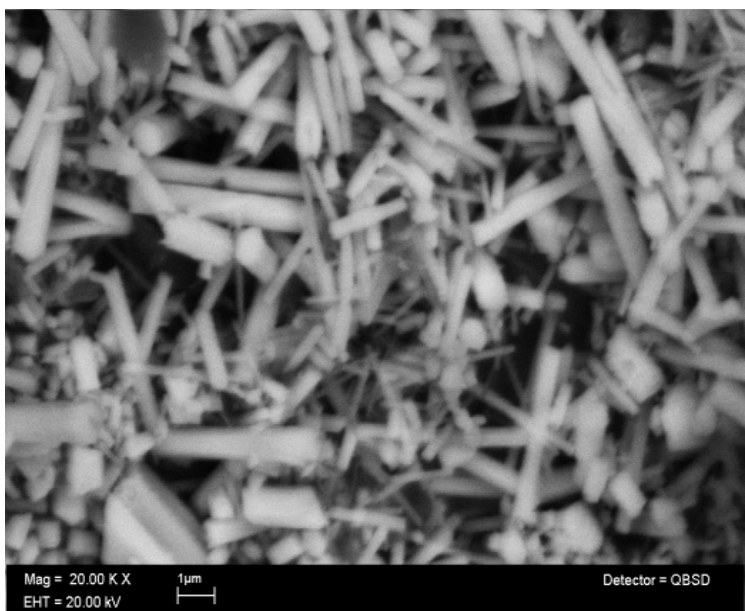

(b)

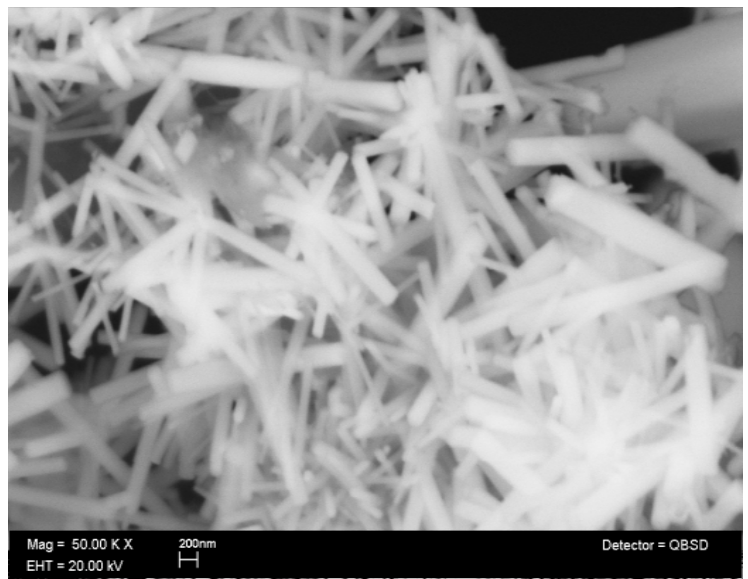

(d)

Figure 2. (a) and (b) low and (c) and (d) high-magnification SEM images of ZnO nanorods.

$\mathrm{nm}$ and lengths of $4 \mu \mathrm{m}$. From the amplified SEM image shown in Figures 2(c) and (d) can be see the hexagonal cross section of the nanorods structures, highly dispersed and without any aggregation between them. This results are in good agreement with the results obtained by Zhang and Narges $[48,49]$.

Figures 3(a) and (b) show the selected area electron diffraction (SAED) pattern and HRTEM image of a nanorod respectively. As can be see, this results show a good crystalline quality of the obtained material, which is consistent with the before XRD result obtained in Figure 1. The (SAED) pattern showed in Figure 3(a) reveal that the nanorods have a single crystal hexagonal structure without dislocations. The HRTEM image reveals that the nanorods preferably growth along the [002] direction (c axis), however, the image also reveals that the interplanar spacing (d) in the crystalline nanorods is $0.26 \mathrm{~nm}$, which represent the distance between [002] planes of the hexagonal $\mathrm{ZnO}$ phase.

Figure 4 shows the room temperature photoluminescence (PL) measurement of the $\mathrm{ZnO}$ nanorods, the

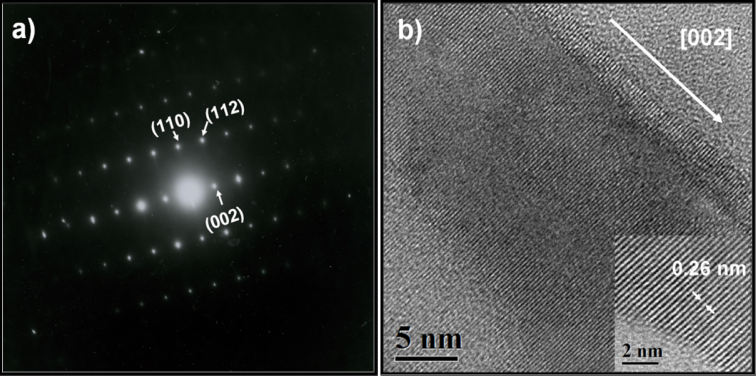

Figure 3. (a) Electron diffraction pattern from a single nanorod. (b) HRTEM image of a nanorod. The nanorod grows along [002] direction.

$\mathrm{ZnO}$ emission spectrum was obtained using the laser line with a wavelength of $358 \mathrm{~nm}$ from an $\mathrm{He:Cd}$ laser as the excitation source, the emission spectrum presents the two typical emission bands centered the first about $380 \mathrm{~nm}$ and the second with a maximum centered between 500 and $530 \mathrm{~nm}$; the first band is a exciton emission band in the UV region and is caused by the radiative annihilation of excitons, the second is an intense band in the green 


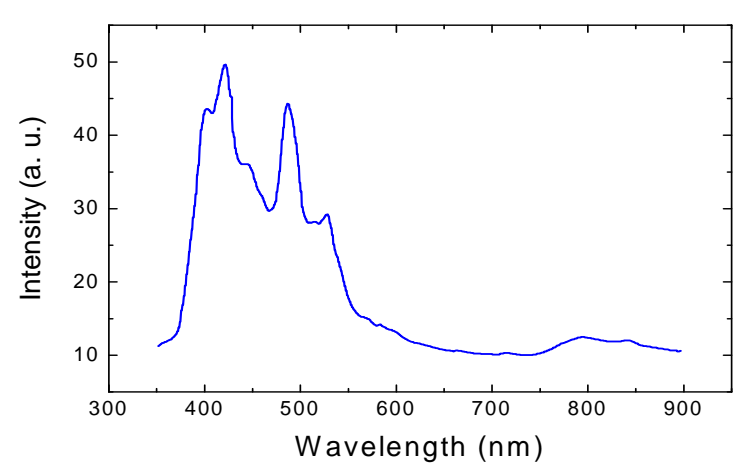

Figure 4. Spectrum of photoluminescence of the $\mathrm{ZnO}$ nanorods under $358 \mathrm{~nm}$ excitation.

region of the visible spectrum produced by the radiative recombination of an electron from a level in the conduction band and an deeply trapped hole in the bulk $\left(\mathrm{V}_{\mathrm{o}}\right)$ of an $\mathrm{ZnO}$ particle [50,51]. However, Figure 4 shows that the intensity of the band visible is less than the intensity of exciton band, this is caused by an effect of particle size as proposed by Van Dijken, which establish that as the size of the $\mathrm{ZnO}$ particles increases the intensity of visible emission decreases and the intensity of exciton emission increase [52]. In this case, from Figure 2 the $\mathrm{ZnO}$ nanorods size $(4 \mu \mathrm{m}$ in length and $400 \mathrm{~nm}$ of diameter) is bigger than Dijken particles resulting thus in an decreasing of the intensity of green visible respect to that of exciton emission.

\section{Conclusions}

In this work $\mathrm{ZnO}$ nanorods were synthesized by the methenamine assisted-hydrothermal method at $90^{\circ} \mathrm{C}$ using Zinc nitrate as precursor and hexamethylenetetramine as surfactant and catalyst.

The analysis SEM revealed that the $\mathrm{ZnO}$ nanorods have a diameter of $400 \mathrm{~nm}$ and length about $4 \mu \mathrm{m}$.

The studies of SAED pattern and HRTEM image made on the nanorods obtained revealed that this material presents an wurtzite structure and all diffraction peaks were indexed to the hexagonal $\mathrm{ZnO}$ phase, having lattice parameters $\mathrm{a}=3.249$ and $\mathrm{c}=5.206 \AA$. Also, from the same studies it is concluded that the nanorods growth along the [002] direction, and the interplanar distance is $0.26 \mathrm{~nm}$.

The photoluminescence spectrum taken to the $\mathrm{ZnO}$ nanoros shows two bands: the first is an exciton emission band in the UV region centered at $380 \mathrm{~nm}$. The second is an intense band in the green region with a maximum in between 500 and $530 \mathrm{~nm}$.

\section{Acknowledgements}

The authors wish to thank Adriana Tejeda (IIM) for his support in carrying out X-ray measurements; Omar Novelo (IIM) for their support in the scanning electron microscopy characterization, M. Canseco-Martínez by his support in chemical reactions. The authors are, also, thankful to the Central Microscopy facilities of the Institute of Physics, UNAM, for providing the microscope tools used in this work.

\section{REFERENCES}

[1] M. H. Huang, S. Mao, H. Fick, et al., "Room-Temperature Ultraviolet Nanowire Nanolasers," Science, Vol. 292, No. 5523, 2001, pp. 1897-1899. doi:10.1126/science.1060367

[2] J. H. Hu and R. G. Gordon, "Atmospheric Pressure Chemical Vapor Deposition of Gallium Doped Zinc Oxide Thin Films from Diethyl Zinc, Water, and Triethyl Gallium," Journal of Appied Physics, Vol. 72, No. 11, 1992, p. 5381. doi:10.1063/1.351977

[3] Y. H. Ko and J. S. Yu, "Structural and Antireflective Properties of ZnO Nanorods Synthesized Using the Sputtered ZnO Seed Layer for Solar Cell Aplications," Journal for Nanoscience and Nanotechnology, Vol. 10, No. 12, 2010, pp. 8095-8101. doi:10.1166/jnn.2010.3020

[4] T. Pompe, V. Srikan and D. R. Clarke, "Acoustoelectric Current Saturation in C-Axis Fiber-Textured Polycrystalline Zinc Oxide Films," Applied Physics Letters, Vol. 69, No. 26, 1996, p. 4065. doi:10.1063/1.117819

[5] D. M. Bagnall, Y. Chen, Z. Zhu, et al., "Optically Pumped Lasing of $\mathrm{ZnO}$ at Room Temperature," Applied Physics Letters, Vol. 70, No. 17, 1997, p. 2230. doi:10.1063/1.118824

[6] L. N. Protasova, E. N. Rebrov, K. L. Choy, et al., "ZnO Based Nanowires Grown by Chemical Vapor Deposition for Selective Hydrogenation of Acetilene Alcoholes," Catalysis Science \& Technology, Vol. 1, No. 5, 2011, pp 768-777. doi:10.10.39/eley0007-4h

[7] Y. Zhang, K. yu, D. Jang, et al., "Zinc Oxide Nanorod and Nanowire for Humidity Sensor," Applied Surface Science, Vol. 242, No. 1-2, 2005, pp. 212-217. doi:10.1016/j.apsusc.2004.08.013

[8] M. Matsui, Y. Hashimoto, K. Funabiki, et al., "Application of Near-Infrared Absorbing Heptamethine Cyanine Dyes as Sensitizers for Zinc Oxide Solar Cell," Synthetic Metals, Vol. 148, No. 2, 2005, pp. 147-153. doi:10.1016/j.synthmet.2004.09.026

[9] R. Vidia Sagar and S. Buddhudu, "Structural and Magnetic Properties of $\mathrm{Co}^{2+}: \mathrm{ZnO}$ Nanoparticles," Advanced Science Letters, Vol. 3, No. 4, 2010, pp. 461-464. doi:10.1166/asl.2010.1141

[10] G. Z. Wang, N. G. Ma,C. J. Deng, et al., "Large-Scale Synthesis of Aligned Hexagonal ZnO Nanorods Using Chemical Vapor Deposition," Materials Letters, Vol. 58, No. 16, 2004, pp. 2195-2198. doi:10.1016/j.matlet.2004.01.020

[11] J. H. Choy, E. S. Jang, J. H. Won, et al., "Soft Solution Route to Directionally Grown ZnO Nanorod Arrays on Si Wafer; Room-Temperature Ultraviolet Laser," Advanced Materials, Vol. 15, No. 22, 2003, pp. 1911-1914. doi:10.1002/adma.200305327

[12] V. A. Roy, A. B. Djurissic, W. K. Chang, et al., "Lumi- 
nescent and Structural Properties of $\mathrm{ZnO}$ Nanorods Prepared under Different Conditions," Applied Physics Letters, Vol. 83, No. 1, 2003, pp. 141-143.

doi:10.1063/1.1589184

[13] L. Vayssieres, "Growth of Arrayed Nanorods and Nanowires of $\mathrm{ZnO}$ from Aqueous Solution," Advanced Materials, Vol. 15, No. 5, 2003, pp. 464-466. doi:10.1002/adma.200390108

[14] P. si, X. Bian, H. Li, et al., "Synthesis of ZnO NanoWhiskers by Simple Method," Materials Letters, Vol. 57, No. 24-25, 2003, pp. 4079-4082. doi:10.1016/S0167-577X(03)00269-6

[15] S. K. Tiku, C. K. Lau and K. M. Lakin, "Chemical Vapor Deposition of ZnO Epitaxial Films on Sapppire," Applied Physics Letters, Vol. 36, No. 4, 1980, p. 318. doi:10.1063/1.91477

[16] M. Kasuga and M. Mochizuky, "Orientation Relationship of Zinc Oxide on Sappire in Hetereoepitaxial Chemical Vapor Deposition," Journal of Crystal Growth, Vol. 54, No. 2, 1981, p. 185. doi:10.1016/0022-0248(81)90459-0

[17] H. B. Kang, K. Nakamura, S. H. Lim, et al., "Epitacxial Growth of ZnO Films On (0001) Sapphire at Low Temperatures By EElectron Ciclotron Resonance Assisted Molecular Beam Epitaxy and Their Microstructural Characterization," Japanese Journal of Applied Physics, Vol. 37, No. 1, 1998, pp. 781-785. doi:10.1143/JJAP.37.781

[18] Q.-B. Ma, Z.-Z. Ye, H.-P. He, et al., "Structural, Electrical and Optical Properties of Transparent Conductive Zno:Ga Films Prepared by DC Reactive Magnetrón Sputtering," Journal of Crystal Growth, Vol. 304, 2007, p. 64.

[19] M. Fujita, N. Kawamota, T. Tatsumi, et al., "Molecular Beam Epitaxial Growth of $\mathrm{ZnO}$ on $\mathrm{Si}$ substrate Using Ozono as an oxigen Sourse," Japanese Journal of Applied Physics Part 1, Vol. 42, No. 1, 2003, pp. 67-70. doi:10.1143/JJAP.42.67

[20] N. Kawamoto, M. Fujita, T. Tatsumi, et al., "Growth of $\mathrm{ZnO}$ on Si substrate By Plasma-Assisted Molecular Beam Epitaxy," Japanese Journal of Applied Physics Part 1, Vol. 42, No. 12, 2003, pp. 7209-7212. doi:10.1143/JJAP.42.7209

[21] C. S. Lao, P. X. Gao, R. S. Yang, et al., "Formation of Double-Side Teethed Nanocoms of $\mathrm{ZnO}$ and Self-Catalys of Zn-Terminated Polar Surface," Chemical Physics Letters, Vol. 417, 2005, pp. 359-363. doi:10.1016/j.cplet.2005.10037

[22] Z. L. Wang, X. Y. Kong and J. M. Zuo, "Induced Growth of Asymmetric Nanocantilever Arrays on Polar Surfaces," Physical Review Letters, Vol. 91, No. 18, 2003, Article ID: 185502. doi:10.1103/PhysRevLett.91.185502

[23] X. Y. Kong, Y. Ding, R. S. Yang and Z. L. Wang, "Single-Crystal Nanorings Formed By Epitaxyal Self-Coilling of Polar Nanobelts," Science, Vol. 303, No. 5662, 2004, pp. 1348-1351. doi:10.1126/science.1092356

[24] X. Y. Kong and Z. L. Wang, "Spontaneous Polarization Induced Nanohelixes, Nanospring and Nanorings of Piezoelectric Nanobelts," Nano Letters, Vol. 3, No. 12, 2003, pp. 1625-1631. doi:10.1021/n1034463p

[25] X. Y. Kong and Z. L. Wang, "Polar-Surface Dominated
$\mathrm{ZnO}$ Nanobelts and the Electrostatic Energy Induced Nanohelixes Nanorings and Nanospirals," Applied Physics Letters, Vol. 84, No. 6, 2004, pp. 975-977. doi:10.1063/1.1646453

[26] Z. W. Pan, Z. R. Dai and Z. L. Wang, "Nanobelts of Semiconducting Oxides," Science, Vol. 291, No. 5510, 2001, pp. 1947-1949. doi:10.1126/science. 1058120

[27] P. X. Gao and Z. L. Wang, "Mesoporous-Polyhedral Cages and Shells Formed By Textured Self-Assambly," Journal of the American Chemical Society, Vol. 125, No. 37, 2003, pp. 11299-11305. doi:10.1021/ja035569p

[28] S. López-Romero, P. Santiago and D. Mendoza, "Assisted-Hydrothermal Synthesis of ZnO Flowerlike Nanostructures," Advanced Science Letters, Vol. 4, 2011, pp. $1-5$.

[29] M. H. Huang, Y. Y. Wu, H. Feick et al., "Catalytic Growth of Zinc-Oxide Nanowires by Vapor Transport," Advanced Materials, Vol. 13, No. 2, 2001, pp. 113-116.

[30] N. Kiomarsipour and R. S.Razavi, "Characterization and Optical Properties of $\mathrm{ZnO}$ Nanosubmicrorods Synthesized by Hydrothermal Method on a Large-Scale," Superlatices and Microstructures, Vol. 52, No. 4, 2012, pp. 704-710. doi:10.1016/j.spmi.2012.07.003

[31] Y. W. Wang, L. D. Zhang, G. Z. Wang, et al., "Catalytic Growth of Semiconducting Zinc Oxide Nanowires and Their Photoluminescence Properties," Journal of Crystal Growth, Vol. 234, No. 1, 2002, pp. 171-175. doi:10.1016/S0022-0248(01)01661-X

[32] K. Sue, K. Kimura, M. Yamamoto, et al., "Rapid Hydrothermal Synthesis of ZnO Nanorods without Organics," Materials Letters, Vol. 58, No. 26, 2004, pp. 3350-3352. doi:10.1016/j.matlet.2004.06.036

[33] Z. R. Dai, Z. W. Pan and Z. L. Wan, "Novel Nanostructures of Functional Oxides Synthesised by Thermal Evaporation," Advanced Functional Materials, Vol. 13, No. 1, 2003, pp. 9-24. doi:10.1002/adfm.200390013

[34] R. S. Wagner and W. C. Ellis, "Vapor-Liquid Solid Mechanism of Crystal Growth," Applied Physics Letters, Vol. 4, No. 5, 1964, pp. 89-90. doi:10.1063/1.1753975

[35] C. Li, Z. Liang, H. Xiao, et al., "Synthesis of $\mathrm{ZnO} /$ $\mathrm{ZnO}_{2} \mathrm{SiO}_{4} / \mathrm{SiO}_{2}$ Composite Pigments with Enjanced Reflectance and Radiation Stabilite under Low-Energy Proton Radiation," Materials Letters, Vol. 64, No. 18, 2010, pp. 1972-1974. doi:10.1016/j.matlet.2010.06.027

[36] S. M. Peng, Y. K. Su, L. W. Ji, et al., "Zinc Oxide TinFilms Transistor with Location-Controlled Crystal Grains Fabricated by Low-Temperature Hydrothermal Method," IEEE Electron Device Letters, Vol. 32, No. 4, 2011, pp. 533-535. doi:10.1109/LED.2011.2104410

[37] O. Akhavan, M. Mehravian, K. Mirabbaszadh, et al., "Hydrothermal Synthesis ofZnO Nanorod Arrays for Photocatalitic Inactivation of Bacteria," Journal of Physics D: Applied Physics, Vol. 42, No. 22, 2009, Article ID: 225305. doi:10.1088/0022-3727/42/22/225305

[38] B. D. Yao, Y. F. Chan and N. Wang, "Formation of ZnO Nanostructures by a Simple Way of Thermal Evaporation," Applied Physics Letters, Vol. 81, No. 4, 2002, pp. 757-759. doi:10.1063/1.1495878

[39] X. D. Wang, J. H. Song and Z. L.Wang, "Nanowire and 
Nanobelt Arrays of Zinc Oxide from Synthesis to Properties and the Novel Devices," Journal of Materials Chemistry, Vol. 17, No. 8, 2007, pp 711-720.

[40] Y. C. Kong, D. P. Yu, B. Zhang, et al., "Ultravioletemitting ZnO Nanowires Synthesized by a Physical Vapor Deposition Approach," Applied Physics Letters, Vol. 78, No. 4, 2001, p. 407. doi:10.1063/1.1342050

[41] Y. Dai, Y. Zhang, Q. K. Li, et al., "Synthesis and Optical Properties of Tetrapod-Like Zinc Oxide Nanorods," Chemical Physics Letters, Vol. 358, No. 1-2, 2002, pp. 83-86. doi:10.1016/S0009-2614(02)00582-1

[42] O. Milosevic and D. Uskokovic, "Synthesis of $\mathrm{BaTiO}_{3}$ and $\mathrm{ZnO}$ Varistor Precursor Powders by Reaction Spray Pyrolysis," Materials Science and Engineering A, Vol. 168, No. 2, 1993, pp. 249-252. doi:10.1016/0921-5093(93)90736-X

[43] J. Zhang, L. D. Sun, C. L. Siao, et al., "A Simpleroute towards Tubular ZnO," Chemistry Communications, No. 3, 2002, pp. 262-263. doi:10.1039/b108863g

[44] L. Guo,Y. L. Ji, H. Xu, et al., "Regularly Shaped Single-Crystaline Nanorods with Wurtzita Structure," Journal of the American Chemical Society, Vol. 124, No. 50, 2002, pp. 14864-14865. doi:10.1021/ja027947g

[45] L. Vassieres, K. Keis, S. E. Lindquist, et al., "PurposeBuilt Anisotropic Metal Oxide Materials: 3D Highly Oriented Arrays of ZnO," Journal of Physics and Chemistry B, Vol. 105, No. 17, 2001, pp. 3350-3352. doi:10.1021/jp010026s

[46] C.-H. Hung and W.-T. Whang. "A Novel Low-Temperature Growth and Characterization of Single Crystal $\mathrm{ZnO}$ Nanoros," Materials Chemistry and Physics, Vol. 82, No.
3, 2003, pp. 705-710. doi:10.1016/S0254-0584(03)00331-6

[47] S. L. Zhung, J. H. Yang, X. L. Yu, et al., "Synthesis, Structures, Photoluminescence, and Teoretical Studies of d10 Metal Complexes of 22-Dihydroxy-[1,1]binaphtalenyl3,3-dicarboxilate," Inorganic Chemistry, Vol. 43, No. 2, 2004, pp. 830-838. doi:10.1021/ic034847i

[48] B. P. Zhang, N. T. Binh and Y. Segawa. "Critical Properties of $\mathrm{ZnO}$ Rods Formed by Metalorganic Chemical Vapor Deposition," Applied Physics Letters, Vol. 83. No. 8, 2003, pp. 1635-1637. doi:10.1063/1.1605803

[49] N. Kiomarsipour and R. S. Razavi, "Characterization and Optical Properties of ZnO Nano-,Submicro- and Microros Synthesized by Hydrothermal Method on a Large-Scale," Superlatice and Microstructures, Vol. 52, No. 4, 2012, pp. 704-710. doi:10.1016/j.spmi.2012.07.003

[50] S. Music, A. Saric and S. Popovic, "Dependence of the Microstructural Properties of $\mathrm{ZnO}$ Particles on Their Synthesis," Journal of Alloys and Compounds, Vol. 448, No. 1-2, 2008, pp. 277-283. doi:10.1016/j.jallcom.2006.10.021

[51] S. Monticone, R. Tufeu and A. V. Kanaev, "Photoluminescence Behavior of Purpose-Built ZnO Arrays on Different Growth Substrates," Journal of Physics and Chemistry B, Vol. 102, No. 16, 1998, pp. 2854-2862. doi:10.1021/jp973425p

[52] A. Van Dijken, E. A. Meulenkamp, D. Vanmaekelberggh, et al., "The Luminescence of Nanocrystaline ZnO Particles: The Mechanism of the Ultraviolet and Visible Emission," Journal of Luminescence, Vol. 87-89, 2000, pp. 454-456. doi:10.1016/S0022-2313(99)00482-2 